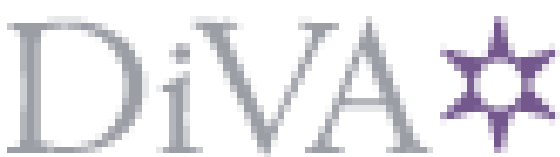

http://www.diva-portal.org

This is the accepted version of the paper published and presented at the $8^{\text {th }}$ International Conference on Research into Design (ICoRD) 2021.

The published paper can be found at:

https://link.springer.com/chapter/10.1007/978-981-16-0119-4 61

Note: When citing this work, cite the originally published paper. 


\title{
The influence of industry 4.0 on product design and development: Conceptual foundations and literature review
}

\author{
Sravan Tatipala ${ }^{1 *}[0000-0002-8601-6825]$, Tobias Larsson $^{1[0000-0002-9662-4576]}$, \\ Christian Johansson ${ }^{1[0000-0003-4875-391 X]}$, and Johan Wall ${ }^{1[0000-0002-7804-7306]}$
}

${ }^{1}$ Blekinge Institute of Technology, Karlskrona, Sweden

sravan.tatipala@bth.se

\begin{abstract}
Since its introduction in 2011, industry 4.0 has been coined the "4th industrial revolution" following mechanization, industrialization and IT/automation as the first three, and represents the current trend of automation technologies (cyber-physical systems, internet of things, cloud computing, etc.,) in the manufacturing industry, with their potential for disruption of the manufacturing paradigm as we know it. However, the effect and role of industry 4.0 on the design and development of the new products to be manufactured in industry 4.0 facilities is not clear. This research presents a literature review to; 1 ) understand the concept of industry 4.0 from an implementation (state of practice) viewpoint, 2) learn about approaches and considerations currently deployed for developing products to be produced in manufacturing plants progressively transforming into industry 4.0 environments. Results reveal that the potential of industry 4.0 is underexploited within product design and development, especially in the conceptual stages lacking methods, tools, and approaches. While later stages of the product development (production planning, ramp-up) have received some attention in regards with optimizing production operations, several publications acknowledge its potential to benefit earlier process stages.
\end{abstract}

Keywords: Industry 4.0, Product Development, Conceptual Design, Engineering Design, Design for Industry 4.0, Internet of Things. 


\section{Introduction}

The fourth industrial revolution commonly referred to as industry 4.0 [1], is believed to have a profound impact on various industrial sectors, especially the manufacturing domain [2-3]. Industry 4.0 represents focus on end-to-end digitization of all physical assets and its integration into digital ecosystems with value chain partners [4]. Industry 4.0 is characterized by emerging technologies such as the Internet of Things, additive manufacturing, mobile internet, wireless sensor networks, big data analytics, cloud computing, cyber-physical factories, nanotechnology, interconnectivity of machines, robotics and artificial intelligence [5]. Since a majority of the discussion in the context of industry 4.0 is focused around manufacturing aspects [6] the role and scope of industry 4.0's innovation potential in the product development process is still largely unexplored, particularly in regard to product design decisions. Wettach et al. [7] asserts that the digital transformation sparked by industry 4.0 is meant to be a lot more than a technology-driven change. Over the past few decades, industries have frontloaded their modelling, simulation and design exploration activities with the intention to improve knowledge early-on, make informed decisions already in conceptual stages of the product development process [8] and use this knowledge in manufacturing. Manufacturing plants all over the world, in diverse sectors, are now being upgraded in accordance with industry 4.0. To take full advantage of these investments it is essential to comprehend the interconnectedness between and the effect of industry 4.0 on the product design and development process. Thus, this paper conducts a systematic literature review (SLR) for 1) clarifying the concept of industry 4.0 from an implementation (state of practice) viewpoint; 2) for attaining an overview of the methods, tools and considerations currently employed for product design and development in the context of industry 4.0. The governing research questions are; 1) What are the key components of an industry 4.0-enabled manufacturing facility? and 2) what method, tools and considerations are design teams employing while designing products to be produced in these factories? Additionally, the authors will reflect upon and foster the ongoing discussion of the role of product design and development in the current industrial transformation. 


\section{Research Approach}

The approach employed for carrying out the SLR is based on guidelines presented in [9-10]. The review process can be divided into two stages; planning and execution. The planning stage encompassed defining the search topic, scope, choosing and justifying the choice of database(s), formulating search string(s), defining inclusion criteria and planning analysis procedure. The execution stage involved searching and collecting literature, iteratively pruning through resultant literature, reviewing the references in the collected literature to identify further relevant studies (cross-reference) followed by classification of research into relevant categories and summarization of the review findings.

\subsection{Data collection and analysis}

An overview of the literature review execution is depicted in Figure 1. The source for collecting literature is divided into two categories; source 1 and 2. In order to understand the concept of industry 4.0 from a state of practice viewpoint, the perspectives of global actors were gathered by reading their blog posts, opinion papers, magazines and feature articles. Company specific research literature is gathered using Google Scholar, Scopus and company webpages all of which is collectively termed as source 1 . To learn about methods, tools and considerations currently employed while designing products for industry 4.0 environments, Scopus database is used due to the wide range of peer-reviewed scientific literature it offers and its proven relevance in the field of research which constitutes source 2. To identify further relevant studies, backward search [11] was conducted by reviewing references of the papers previously gathered (crossreference). Other relevant databases such as Web of Science or EBSCO are excluded from the current review since the study is initial in nature. In addition, [12-13] is referred to gather background knowledge on traditional approaches to conduct manufacturing, assembly, cost assessments during product development. 


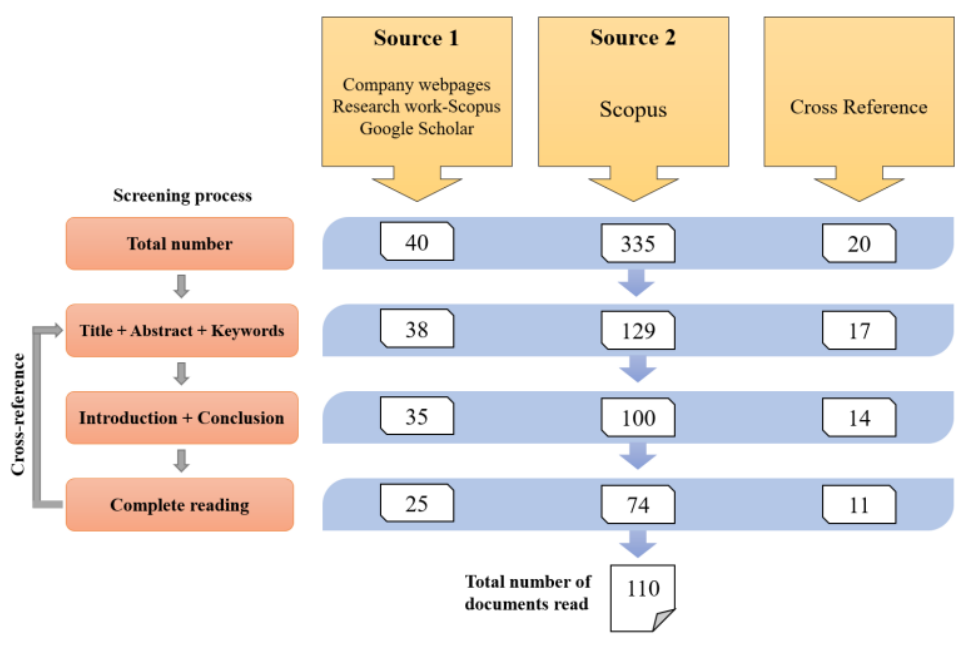

Fig. 1. Overview of the literature review execution (inspired from [14])

The search string used in source 2 is as follows; ( TITLE-ABS-KEY ("product development" $O R$ "product innovation" OR "product design" $O R$ "engineering design" $O R$ "preliminary design" $O R$ "concept* design" $O R$ "concept* develop*" $O R$ "early design" $O R$ "initial design" $O R$ "fuzzy front end" OR "design space exploration") AND TITLE-ABS-KEY ( \{Industry 4.0\} $O R$ \{fourth Industrial revolution\} $O R$ \{design for industry 4.0\} OR \{cyber physical system\} OR \{cyber-physical system\}) AND TITLE-ABS-KEY ( "manufactur*" OR "production" OR "smart manufactur*" OR "digital manufactur*" OR "flexible manufactur*" ) ) AND (LIMIT-TO ( LANGUAGE, "English")) AND (LIMIT-TO (DOCTYPE, "cP") OR LIMITTO (DOCTYPE, "ar")). The search string forces the result to involve three domains namely, product design and development, manufacturing process and industry 4.0, resulting in literature with overlapping research domains. Search operators "AND" and "OR" are used due to the fragmentation of literature in the area in addition to wildcard character "*" to retrieve variations of a word. The search resulted in 335 hits with 1 duplicate hit which was eliminated. Only conference and journal papers in English were considered. The screening process involved three steps as shown in figure 1 . To be qualified as relevant, the papers had to consider design aspects with regard to manufacturing during the product development process in the context of industry 4.0. Papers not addressing 
product or production system or related design aspects in connection with manufacturing were excluded. Literature from source 2 was exempted from this criterion to grasp the concept of industry 4.0 in its entirety. Every paper from the finalized set was fully read, summarized in one or more sentences, mapped into relevant categories followed by trend analysis.

\section{Review findings}

\subsection{Industry 4.0 and its key components}

Since the German initiative "Industrie 4.0" appeared in 2011 [1], marking the dawn of the fourth industrial revolution, it has received increased attention from several industrial sectors. In 2013, the "Industrie 4.0 working group" published first recommendations [15] for the implementation of industry 4.0, detailing its vision, enablers and some application scenarios. Despite its popularity, companies still struggle to grasp the idea of Industry 4.0 [16] with diverse perceptions of the concept [17] and manifold review papers [18-19]. Besides, very few real-life examples of industry 4.0 exist [20] with most being lab-scale or novice industrial implementations. Three key and commonly accepted components of industry 4.0 have emerged in literature as; Cyber-Physical Systems (CPS), Internet of Things (IoT), and Smart Factory. CPS is the integration of computation, networks and physical processes in which embedded computers monitor and control physical processes through networks while physical processes in turn affect computation through closed feedback loops [21]. CPS enables an important feature of industry 4.0 which is the fusion of the physical and virtual worlds [17]. loT is the network used to connect smart components (e.g., sensors, actuators, logistics, tablets) in a factory allowing data transmission, interaction and cooperation for synergistic operation [17]. Smart factory is a context-sensitive manufacturing environment that assists machines and humans in execution of complex tasks efficiently [22]. 
Hence, Industry 4.0 is an umbrella term encapsulating digital technologies and the aforementioned concepts aimed at enhancing current industrial operations [20] while meeting challenges such as growing sustainability requirements, fluctuating market demands, shorter development times as well as increased appeal for customized products and integrated lifecycle solutions like product-service systems [23]. In an industry 4.0 environment, smart factories consist of CPS that are capable of autonomously exchanging information, triggering actions and controlling each other over loT infrastructures [17]. Smart products in these factories are uniquely identifiable, can be located at all times, are aware of their current status/history and can navigate routes to achieve target state [15]. Furthermore, industry 4.0 aims to realize end-to-end digital integration of engineering across industrial value chains and business processes, a digital model-driven process from start to end [23]. Empirical evidences for the implementation of industry 4.0 concept is presented in [20].

\subsection{Role of design in the realm of industry 4.0}

Figure 2 (left) illustrates the most significant economic opportunities of industry 4.0 according to a global survey [24] interviewing experts within six nations. Amongst others, production optimization is seen as one of the main economic benefits. Furthermore, [6] acknowledges that most of the research in the context of industry 4.0 is concentrated around improving manufacturing operations while some publications $[6-7,17,25]$ admit the importance of design for the successful implementation of industry 4.0. Regarding design, both design of production systems as well as the design of products to be produced in these systems are of interest. Patil et al. [26] and Bertoni et al. [27] assert the need to alter our product design and development strategies, which, in the context of industry 4.0, are meant to support continuous improvement over the entire product lifecycle using real-time product data. For example, unlike the traditional way of developing products in discrete generations, $\mathrm{ABB}$ and Tesla collect data from their products in use to release new features via software updates [28]. The role of design in actualizing industry 4.0 is further emphasized by [7] which claims that "without design, industry 4.0 will fail" and presents six 
areas where design accelerates successful digital transformation in manufacturing. Likewise, [29] urges the need to combine knowledge from different disciplines and create sharing platforms since exclusive reliance on traditional engineering is no longer sufficient with design practices at the core of the digital revolution. Research also reports that investing in technology alone cannot meet the challenge of this digital transformation [30] and that industry 4.0 is meant to be a lot more than a technology-driven change [7]. Since the product design and development process defines the value chain for a company to a large extent, design is believed to play a major role in fully benefiting from the fourth industrial revolution [25].
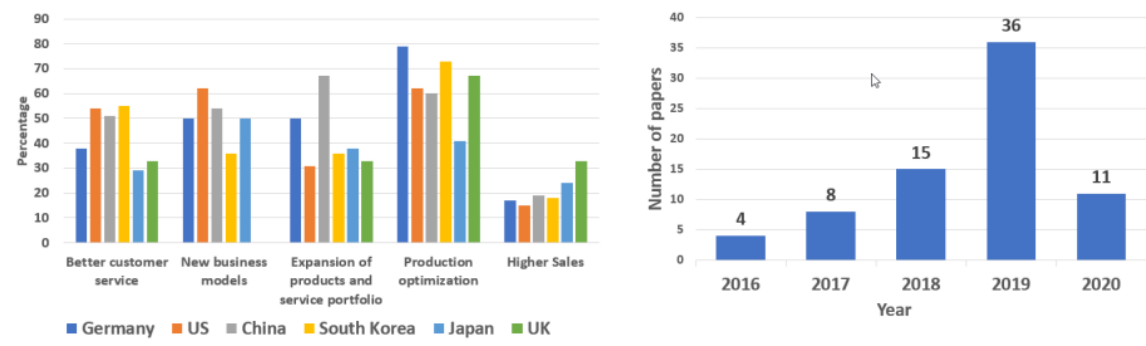

Fig. 2. Most significant economic opportunities of industry 4.0 based on a global survey [24] (left) and categorization of papers gathered from source 2 based on publication year (right)

\subsection{Manufacturing considerations during product design and development in the context of industry 4.0.}

This section presents analysis of papers from source 2 . The product development process as presented by Ulrich and Eppinger in [12] is taken as a reference due to its generality. Figure 3 (left) shows categorization of literature based on application domain. The single most popular field is automotive (12 papers) followed by aerospace ( 8 papers). The majority (34 papers) fall under the general category in which research conducted does not belong to a specific domain. A deeper look reveals that these papers are published by research organizations and universities depicting the research topic's popularity. Other industrial sectors such as shipping, 
chemical, railways, and construction industries ( 6 papers) are beginning to show interest in addition to electronics and food sectors (14 papers). From a time perspective, figure 2 (right) shows a constant rise in the number of publications focusing on product design and development in the context of industry 4.0, with exponential growth over the past four years. Figure 3 (right) shows the classification based on the 'focus' of papers. While the focus of the majority (22 papers) is centered on manufacturing costs, material, process and assembly assessments, research reviewing and proposing overall process frameworks/architectures for industry 4.0 implementation (13 papers) has received significant interest. Similarly, papers focused on design features for facilitating aspects such as customizability, robustness, smartness have attracted good attention (12 papers), although presenting only initial studies. Likewise, production planning, analysis and management approaches have received good attention (11 papers). The category concerning conceptual design of products has received the least attention (4 papers) while other aspects such as factory optimization, quality improvement, additive manufacturing, sustainability, were the focus of 12 papers.
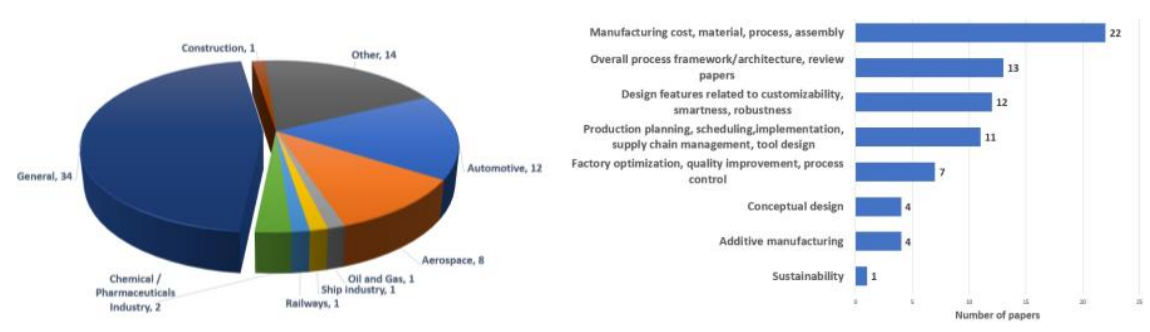

Fig. 3. Illustration showing the number of papers categorized based; on the application domain (left) and research focus (right)

Considering the methods, tools and approaches used in the analyzed papers (see figure 4, left), it is seen that a vast majority are employing traditional methods such as Design for Manufacturing/Assembly (DFMA) (20 papers) and Design for X (DFX) (5 papers), either directly or with modifications to suit industry 4.0 factory features such as flexibility [31], cyberphysical systems [32], customizability [33], recyclability [34]. Likewise, considerable papers present generic methods (16 papers) in addition to 
specific methods (10 papers) to support development of industry 4.0 solutions. These methods involve technologies such as augmented reality [35] virtual reality [36], digital twins [37], cloud-based platforms [38], while some of these methods support specific design aspects such as integrability between product design and manufacturing [39], design of product quality monitoring systems [40], intelligent product design with CPS feedback [41], CPS user interface design [42], loT-based systems [43].
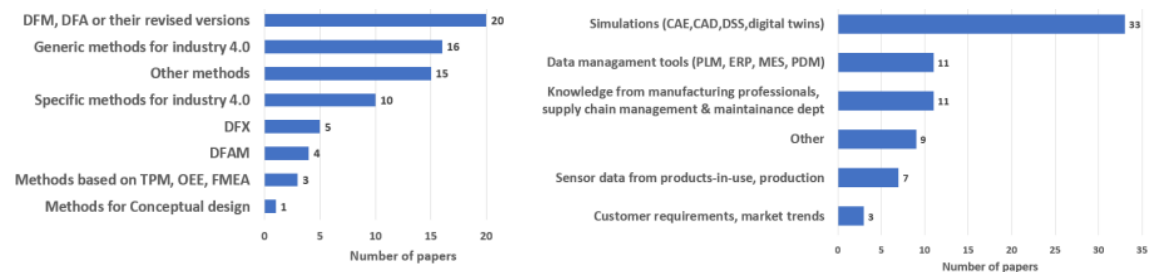

Fig. 4. Categorization of papers based on methods/tools/approaches employed (left) and sources of feedback (right)

15 papers were assigned to 'other' category, which involved methods featuring simulations, automated/smart/generative design, knowledge feedback, product lifecycle management (PLM) and manufacturing execution system (MES) tool-based approaches as well as review papers. Further categories (7 papers) involved methods based on Design for Additive manufacturing (DFAM), failure mode and effect analysis (FMEA), overall equipment effectiveness (OEE) and total productive maintenance (TPM). It is interesting to note that only 1 paper [6] presents a method contributing to conceptual design. Considering the source of feedback or information used in the presented methods (see figure 4, right), it is observed that the majority (20 papers) use insights generated through simulations (in e.g. CAE, digital twins, CAD, DSS) or based on common data management tools (PLM, PDM, ERP, MES) (11 papers). Similarly, several (11 papers) utilize manufacturing professionals' knowledge, maintenance department logs as well as information from supply chain management to serve as feedback sources. Publications (9 papers) featuring feedback from workshops, literature review, surveys and building information modelling (BIM) were assigned to the 'other' category. Interestingly, some publications ( 7 papers) capitalize on sensor-based data from prod- 
uct-in-use or production. Alternative sources for feedback include customer requirements and market trends (3 papers).

\section{Discussion}

Industry 4.0 creates promising opportunities for producing low-volume, on-demand custom products, and realizing end-to-end digital integration of engineering across value chains [15], while enhancing the digital flow of information between product developers, manufacturing engineers, and global suppliers to accelerate innovation, reduce risk and seek competitive advantage. Concepts such as concurrent and simultaneous engineering as well as collaborative design have existed for several years [44]. Claims like " $80 \%$ of the manufacturing costs of a product is determined by product design" were popular amongst research publications already since the 90s [45]. Likewise, DFX methodologies have been widely practiced by design teams for cost reduction while guiding designs to meet quality criteria related to robustness, reliability, serviceability, and manufacturability, to name a few. Amongst these, DFM and DFA were the most popular methods since it directly addresses manufacturing and assembly costs [12]. The review analysis reveals the prominence of these methods even today, which are used either directly or with modifications (based on research and development) to suit industry 4.0. However, these methods do not encompass comprehensive features to foster the overall industry 4.0 "ideology". For example, they lack aspects such as, assessment of the relationship between complex industrial systems and product design features, utilization of IoT sensor data or product lifecycle data for identifying new design features [43], thorough design space exploration schemes to guide relevant design features, orchestration of industry 4.0 elements to support trade-offs, to name a few. Their role in industry 4.0 will be determined via the interoperability with new solutions based on industry 4.0. The authors recognize a need for research in this regard to deal with the complexity triggered by the fusion of physical and digital worlds within smart factories, to guide design and support decision making during the product development process. Of the publications proposing specific methods for the design of and for industry 4.0 solutions, sev- 
eral employ model-based engineering principles suggesting promising prospects for future research pursued in this direction. Additionally, the review highlights two promising concepts in the context of industry 4.0; product generation engineering (PGE) [46], which suggests that new products are almost always based on one or more existing product generations [6], and technical inheritance, which proposes to identify, transfer and use targeted information from product lifecycle to develop next generation products [47]. The past decades have seen a rise in the use of computer tools to virtually develop, simulate, test, and validate design solutions. This is in agreement when considering sources of feedback or information in the reviewed papers where a majority utilize simulationbased sources. It is interesting to note that approaches still depend on the knowledge, experience, and the intuition of manufacturing professionals. Information gathered in this manner, besides being asynchronous also consumes effort to collect and analyze. The authors argue that with increasing access to digital flow of information from different stages of the product lifecycle there is a need for data-driven procedures to provide a quicker and synchronous stream of information for aiding product development process in real-time. Singh et al. [8] exemplifies the possibility of leveraging digital thread (which is defined as a data-driven architecture linking product lifecycle data [8]) to produce efficient design of the next generation of products. Most importantly, the review identifies a lack of research aimed at conceptual stages of product design in the context of industry 4.0. Although Simulation-, Value-, and Data-Driven Design frameworks [23, 48-50] assist conceptual design assessments, these struggle to deal with the complexity of manufacturing process performance and industry 4.0 aspects. The authors assert a need for further research in this regard.

\section{Conclusion}

The paper presents results of a systematic literature review investigating key components of industry 4.0 and surveying its role in the product design and development process. Despite its popularity, companies struggle to grasp the concept of industry 4.0 in its entirety with many understand- 
ing the focus to be optimization of manufacturing operations. The review shows that research within product design and development in the context of industry 4.0 is scarce of which most are focused on later stages such as production system design and planning with very few in the earlier stages. The authors argue that current design approaches are not fully capitalizing on digital flow of information from different stages of the product lifecycle, which are increasingly synchronous. Furthermore, the authors acknowledge the need to consider aspects beyond manufacturing process, material and assembly procedures and focus on for example, identifying appropriate design features based on loT sensor data, examining the relationship between complex industrial systems and product design to facilitate early tradeoffs, building methods to support development of lifecycle solutions based on digital thread, and creation of designs with reduced failure rates in production to enable low-volume consumercentric products, to name a few. The presented trends and analysis summary aims to highlight the role of design in digital transformation as well as foster the ongoing discussion on the research topic.

\section{References}

1. Kagermann, H., Lukas, W. D., \& Wahlster, W. (2011). Industrie 4.0: Mit dem Internet der Dinge auf dem Weg zur 4. industriellen Revolution. VDI nachrichten, 13(1).

2. Bartodziej, C. J. (2017). The concept industry 4.0: An Empirical Analysis of Technologies and Applications in Production Logistics. In The concept industry 4.0 (pp 27-50). Springer Gabler, Wiesbaden.

3. Almada-Lobo, F. (2015). The Industry 4.0 revolution and the future of manufacturing execution systems (MES). Journal of innovation management, 3(4), 16-21.

4. Lee, M. X., Lee, Y. C., \& Chou, C. J. (2017). Essential implications of the digital transformation in industry 4.0. J. Sci. Ind. Res. 76, 465-467.

5. Wang, S., Wan, J., Zhang, D., Li, D., \& Zhang, C. (2016). Towards smart factory for industry 4.0: a self-organized multi-agent system with big data based feedback and coordination. Computer Networks, 101, 158-168.

6. Albers, A., Stürmlinger, T., Mandel, C., Wang, J., de Frutos, M. B., \& Behrendt, M. (2019) Identification of potentials in the context of Design for Industry 4.0 and modelling of interdependencies between product and production processes. Procedia CIRP, 84, 100-105.

7. Wettach et al. (2018). Without design, Industry 4.0 will fail: Six challenges where design accelerates successful digital transformation in manufacturing. In IXDS Human Industries Venture. Retrieved from (https://www.ixds.com/without-design-industry-40-willfail). 
8. Singh, V., \& Willcox, K. E. (2018). Engineering design with digital thread. AIAA Journal, 56(11), 4515-4528.

9. Biolchini, J., Mian, P. G., Natali, A. C. C., \& Travassos, G. H. (2005). Systematic review in software engineering. System Engineering and Computer Science Department COPPE/UFRJ, Technical Report ES, 679(05), 45.

10. Thomas, D. R., \& Hodges, I. D. (2010). Doing a literature review. In Designing and managing your research project: Core skills for social and health research. Sage Publications.

11. Webster, J., Watson, R.T., 2002. Analyzing the past to prepare for the future: writing a literature review. MIS Q. 26 (2).

12. Ulrich, K. and Eppinger, S., 2012, Product Design and Development, McGraw Hill. Inc., New York. ISBN 9780071137423

13. Sandberg, M. (2007). Design for manufacturing: methods and applications using knowledge engineering (Doctoral Thesis, Luleå tekniska universitet).

14. da Costa Fernandes, S., Pigosso, D. C., McAloone, T. C., \& Rozenfeld, H. (2020). Towards product-service system oriented to circular economy: A systematic review of value proposition design approaches. Journal of Cleaner Production, 257, 120507.

15. Kagermann, H., Wahlster, W., \& Helbig, J. (2013). Recommendations for implementing the strategic initiative Industrie 4.0: Final report of the Industrie 4.0 Working Group. Forschungsunion: Berlin, Germany.

16. Sanders, A., Elangeswaran, C., \& Wulfsberg, J. P. (2016). Industry 4.0 implies lean manufacturing: Research activities in industry 4.0 function as enablers for lean manufacturing. Journal of Industrial Engineering and Management (JIEM), 9(3), 811-833.

17. Mario, H., Tobias, P., \& Boris, O. (2015). Design principles for Industrie 4.0 scenarios: a literature review. Technische Universität Dortmund, working paper, 1.

18. Xu, L. D., Xu, E. L., \& Li, L. (2018). Industry 4.0: state of the art and future trends. International Journal of Production Research, 56(8), 2941-2962.

19. Oztemel, E., \& Gursev, S. (2020). Literature review of Industry 4.0 and related technologies. Journal of Intelligent Manufacturing, 31(1), 127-182.

20. Da Silva, V. L., Kovaleski, J. L., Pagani, R. N., Silva, J. D. M., \& Corsi, A. (2020). Implementation of Industry 4.0 concept in companies: Empirical evidences. International Journal of Computer Integrated Manufacturing, 33(4), 325-342.

21. Lee, E. A. (2015). The past, present and future of cyber-physical systems: A focus on models. Sensors, 15(3), 4837-4869.

22. Lucke, D., Constantinescu, C., \& Westkämper, E. (2008). Smart factory-a step towards the next generation of manufacturing. In Manufacturing systems and technologies for the new frontier (pp. 115-118). Springer, London.

23. Wall, J., Bertoni, M., Larsson, T. (2020). The Model-Driven Decision Arena: Augmented Decision-Making for Product-Service Systems Design. Systems, 8, 22.

24. Kagermann, H., Anderl, R., Gausemeier, J., Schuh, G., \& Wahlster, W. (Eds.). (2016). Industrie 4.0 in a Global Context: strategies for cooperating with international partners. Herbert Utz Verlag.

25. Pessôa, M. V. P., \& Becker, J. M. J. (2020). Smart design engineering: a literature review of the impact of the 4th industrial revolution on product design and development. Research in engineering design, 1-21.

26. Patil, B. A., Kulkarni, M. S., \& Rao, P. V. M. (2019, December). New Product Development (NPD) Process in the Context of Industry 4.0. In 2019 IEEE International Conference on Industrial Engineering and Engineering Management (IEEM) (pp. 1231-1235). IEEE.

27. Bertoni, A., Larsson, T., Larsson, J., \& Elfsberg, J. (2017). Mining data to design value: A demonstrator in early design. In DS 87-7 Proceedings of the 21st International Conference on Engineering Design (ICED 17) Vol 7: Design Theory and Research Methodology, Vancouver, Canada, 21-25.08. 2017 (pp. 021-029). 
28. Porter, M. E., \& Heppelmann, J. E. (2015). How smart, connected products are transforming companies. Harvard business review, 93(10), 96-114.

29. Celaschi, F. (2017). Advanced design-driven approaches for an Industry 4.0 framework: The human-centred dimension of the digital industrial revolution. Strategic design research journal, 10(2), 97-104.

30. Synnes, E. L., \& Welo, T. (2016). Enhancing integrative capabilities through lean product and process development. Procedia CIRP, 54, 221-226.

31. Karagiannis, P., Matthaiakis, S. A., Andronas, D., Filis, K., Giannoulis, C., Michalos, G., \& Makris, S. (2019). Reconfigurable Assembly Station: A Consumer Goods Industry Paradigm. Procedia CIRP, 81, 1406-1411.

32. Ndip-Agbor, E., Cao, J., \& Ehmann, K. (2018). Towards smart manufacturing process selection in Cyber-Physical Systems. Manufacturing Letters, 17, 1-5.

33. Mourtzis, D., Zogopoulos, V., \& Xanthi, F. (2019). Augmented reality application to support the assembly of highly customized products and to adapt to production re-scheduling. The International Journal of Advanced Manufacturing Technology, 105(9), 3899-3910.

34. Rojek, I., Dostatni, E., \& Hamrol, A. (2018, September). Automation and digitization of the material selection process for ecodesign. In International Conference on Intelligent Systems in Production Engineering and Maintenance (pp. 523-532). Springer, Cham.

35. Bruno, F., Barbieri, L., Marino, E., Muzzupappa, M., D’Oriano, L., \& Colacino, B. (2019). An augmented reality tool to detect and annotate design variations in an Industry 4.0 approach The International Journal of Advanced Manufacturing Technology, 105(1-4), 875-887.

36. Nåfors, D., Berglund, J., Gong, L., Johansson, B., Sandberg, T., and Birberg, J. (2020). Application of a Hybrid Digital Twin Concept for Factory Layout Planning," Smart and Sustainable Manufacturing Systems 4, 2, 231-244.

37. Yi, Y., Yan, Y., Liu, X., Ni, Z., Feng, J., \& Liu, J. (2020). Digital twin-based smart assembly process design and application framework for complex products and its case study. Journal of Manufacturing Systems.

38. Nellippallil, A. B., Ming, Z., Allen, J. K., \& Mistree, F. (2019). Cloud-based materials and product realization-Fostering ICME via Industry 4.0. Integrating Materials and Manufacturing Innovation, 8(2), 107-121.

39. Caputo, F., Caterino, M., De Luca, A., Fera, M., Greco, A., Lamanna, G., MacChiaroli, R., Manco, P., Manzo, M. and Perfetto, D. (2019, June). Product And Process Integrated Design To Enhance Smart Manufacturing Systems. In ECMS (pp. 213-218).

40. Shin, K. Y., \& Park, H. C. (2019, October). Smart Manufacturing Systems Engineering for Designing Smart Product-Quality Monitoring System in the Industry 4.0. In 2019 19th International Conference on Control, Automation and Systems (ICCAS) (pp. 1693-1698). IEEE.

41. CHEN, Y. H., HO, P. H., \& CHIU, M. C. (2015). Utilizing Cyber Physical System to Achieve Intelligent Product Design: A Case Study of Transformer. Transdisciplinary Engineering: A Paradigm Shift, 1031.

42. Stern, H., \& Becker, T. (2019). Concept and evaluation of a method for the integration of human factors into human-oriented work design in cyber-physical production systems. Sustainability, 11(16), 4508.

43. Albers, A. A., Bernijazov, R., Kaiser, L., \& Dumitrescu, R. (2018, June). Internet of Things Canvas for Ideation in Model-Based Product Generation Planning. In 2018 13th Annual Conference on System of Systems Engineering (SoSE) (pp. 327-334). IEEE.

44. Polacsek, T., Roussel, S., Pralet, C., \& Cuiller, C. (2019, May). Design for efficient production, a model-based approach. In 2019 13th International Conference on Research Challenges in Information Science (RCIS) (pp. 1-6). IEEE.

45. Ulrich, K. T., \& Pearson, S. A. (1993). Does product design really determine $80 \%$ of manufacturing cost? 
46. Albers, A., Bursac, N., \& Wintergerst, E. (2015). Product generation developmentimportance and challenges from a design research perspective. New developments in mechanics and mechanical engineering, 16-21.

47. Mozgova, I., Barton, S., Demminger, C., Miebach, T., Taptimthong, P., Lachmayer, R., ... \& Wurz, M. C. (2017). Technical inheritance: Information basis for the identification and development of product generations. In DS 87-6 Proceedings of the 21st International Conference on Engineering Design (ICED 17) Vol 6: Design Information and Knowledge, Vancouver, Canada, 21-25.08. 2017 (pp. 091-100).

48. Bertoni, M., Eres, H., \& Scanlan, J. (2014). Co-creation in complex supply chains: the benefits of a Value Driven Design approach. In Product Development in the Socio-sphere (pp. 35-62). Springer, Cham.

49. Wall, J. (2007). Simulation-Driven Design of Complex Mechanical and Mechatronic Systems (Doctoral Thesis, Blekinge Institute of Technology, Karlskrona, Sweden). Retrieved from http://urn.kb.se/resolve?urn=urn:nbn:se:bth-00346

50. Bertoni, A. (2018). Role and challenges of data-driven design in the product innovation process. IFAC-PapersOnLine, 51(11), 1107-1112. 